\title{
Comparing Autonomous Underwater Vehicle (AUV) and Vessel-based Tracking Performance for Locating Acoustically Tagged Fish
}

\author{
JOHN H. EILER, THOMAS M. GROTHUES, JOSEPH A. DOBARRO, and MICHELE M. MASUDA
}

\section{Introduction}

Detailed information on the movements and distribution of marine species is necessary for stock assessments and, when combined with habitat information, for the implementation of ecosystem-based management (Cadrin and Secor, 2009; Goethel et al., 2011). Establishing baseline data is also becoming increasingly important for assessing changes in population and community structure in relation to environmental shifts in ocean conditions

John H. Eiler and Michele M. Masuda are with the Auke Bay Laboratories, Alaska Fisheries Science Center, National Marine Fisheries Service, NOAA, 17109 Point Lena Loop Road, Juneau, AK 99801. Thomas M. Grothues and Joseph A. Dobarro are with the Rutgers University Marine Field Station, Institute of Marine and Coastal Sciences, Rutgers University, 800 c/o 132 Great Bay Blvd., Tuckerton, NJ 08087. John H. Eiler is the corresponding author (email: john.eiler@noaa.gov).

doi: dx.doi.org/10.7755/MFR.75.4.2
(Perry et al., 2005; Rose, 2005; Doney et al., 2012; Aschan et al., 2013).

Emerging technologies, including acoustic telemetry and remote monitoring with autonomous underwater vehicles (AUV's), can enhance efforts to address research and management issues. Acoustic telemetry, defined here as the detection of fish and other aquatic macrofauna tagged with acoustic transmitters and located using submerged hydrophones (Winter, 1996; Arnold and Dewar, 2001), can provide detailed information on the distribution, movements, and habitat use of marine species.

This approach has many advantages over conventional tagging (i.e., identifying individuals or groups of fish based on external marks or tags) and recovery methods, which provide information based solely on where the tagged individuals were recaptured and can be biased by disproportional recovery efforts, vulnerability to capture, and variable reporting rates
ABSTRACT-Autonomous underwater vehicles (AUV'S) are increasingly used to collect physical, chemical, and biological information in the marine environment. Recent efforts include merging AUV technology with acoustic telemetry to provide information on the distribution and movements of marine fish. We compared surface vessel and AUV tracking capabilities under rigorous conditions in coastal waters near Juneau, Alaska. Tracking surveys were conducted with a REMUS 100 AUV equipped with an integrated acoustic receiver and hydrophone. The AUV was programmed to navigate along predetermined routes to detect both reference transmitters at 20-500 $\mathrm{m}$ depths and tagged fish and crabs in situ. Comparable boat surveys were also conducted. Transmit- ter depth had a major impact on tracking performance. The AUV was equally effective or better than the boat at detecting reference transmitters in shallow water, and significantly better for transmitters at deeper depths. Similar results were observed for tagged animals. Red king crab, Paralithodes camtschaticus, at moderate depths were recorded by both tracking methods, while only the AUV detected Sablefish, Anoplopoma fimbria, at depths exceeding $500 \mathrm{~m}$. Strong currents and deep depths caused problems with AUV navigation, position estimation, and operational performance, but reflect problems encountered by other AUV applications that will likely diminish with future advances, enhanced methods, and increased use.
(Seber, 1982; Buckland, 1980). Individuals tagged with acoustic transmitters can be repeatedly located without having to be captured. This factor can be a major advantage particularly when working in isolated areas or studying species that are sensitive to handling, difficult to catch, or associated with substantial bycatch.

Despite these advantages, the utility of acoustic telemetry can be offset by the limited reception range (typically hundreds of meters) and the tradeoffs between transmitter size, transmitting power and operational life (Arnold and Dewar, 2001; Pincock and Johnston, 2012), and the vast distances, depths, limited access, and adverse conditions (e.g., rough seas, stratification) often encountered in marine waters. To counter these limitations, a variety of methods have been used to actively locate acoustically tagged fish from vessels (Holland et al., 1985; Marsac and Cayre, 1998; Pepperell and Davis, 1999; Brill et al., 2002; Meyer and Holland, 2005; Ng et al., 2007; Taggart et al., 2008).

However, high operational costs and limited vessel availability can significantly reduce vessel-based efforts, especially when working in remote areas. Inclement weather can further impact the amount of time that tracking is feasible, particularly for smaller vessels, and substantially reduce acoustic signal reception (Goodman, 1990; Winter, 1996; Ross and Lueck, 2003). Tracking from larger vessels can be logistically challenging, electronically noisy, and often conflicts with other scheduled tasks or research activities.

Alternatively, stationary receiver/ hydrophone arrays have been used to 
cordon off marine areas and detect tagged individuals moving within reception range (Voegeli et al., 2001; Simpfendorfer et al., 2002; Welch et al., 2003; Grothues and Able, 2007; Bishop et al., 2010). Stationary tracking is less affected by adverse conditions, and allows for the collection of extended time series data of migratory species or fine-scale positioning studies in localized areas. However, this approach is also equipment intensive, often dependent on the local geomorphology, and may be logistically challenging or prohibitively expensive compared to mobile tracking methods.

Both gliders and propelled AUV's can mitigate some of the challenges associated with existing tracking methods by expanding vessel-based capabilities and providing a flexible supplement to stationary arrays, as they have for other applications including military, industrial, and scientific research (Wernli, 2000; Hagen et al., 2003). AUV's are increasingly being used to document physical, chemical, and biological characteristics of the marine environment (Hibbert, 1997; Moline et al., 2005; Jones et al., 2008) and have tremendous potential to provide information on the biology and status of fish populations (Clarke et al., 2010).

Recent efforts have produced AUV's with acoustic telemetry capabilities. At least one AUV equipped with an integrated acoustic receiver and hydrophone is now used routinely as a telemetry platform to locate tagged fish in estuarine and shallow coastal settings in the eastern United States (Grothues et al., 2009, 2010, 2012). In addition to the enhanced tracking capabilities provided by the vehicle, the AUV's high frequency side-scan sonar and environmental sensors make it possible to integrate telemetry data (e.g., fish presence and location) with bathymetric and environmental information. However, until now AUV performance has not been rigorously tested in comparison to vessel-based (i.e., surface) tracking, and never in deep waters where AUV's have demonstrated capabilities for other applications.

We evaluated the performance of an AUV for collecting acoustic telemetry data and associated hydrographic information in coastal waters of southeastern Alaska during May-June 2010. The primary goal of the study - determining the feasibility of using AUV's to track marine animals - focused on both the operational capabilities of the AUV and the performance of the telemetry component of the system. Here we discuss the second of these two issues, with generalized references to the first.

The specific objectives of this portion of the study were to 1) determine the range and fidelity of the AUVbased acoustic receiver/hydrophone system for recording ultrasonic reference transmitters (similar to those used for biotelemetry studies) placed at known locations and depths in a complex marine environment, and 2) compare telemetry data obtained for reference transmitters and free-ranging acoustically-tagged animals using both AUV and vessel-based tracking to determine if AUV platforms provide comparable or better information than conventional methods.

\section{Methods}

\section{Study Area}

The study area, located near Juneau, Alaska (Fig. 1), was chosen because of its demanding conditions and proximity to NOAA's National Marine Fisheries Service (NMFS) support facilities in Auke Bay. The geomorphology of the area is complex with many ocean channels, bays, inlets, and islands. Water depths range from shallow nearshore habitats to depths exceeding 500 m. Extreme tidal fluctuations, freshwater intrusion from local rivers, and strong, highly variable currents further complicate AUV operations. Survey sites within the area were sampled with a CTD (Model 19plus, Sea-Bird Electronics $^{1}$, Bellevue, Wash.) from 11

${ }^{1}$ Reference to trade names or commercial firms does not imply endorsement by the National Marine Fisheries Service, NOAA, or Rutgers University.
May to 18 June 2010 in conjunction with AUV and boat tracking missions. Sampling depth (from surface to ocean floor) ranged from 74 to $92 \mathrm{~m}$ at Portland Island and from 511 to $587 \mathrm{~m}$ at Point Retreat.

\section{Transmitters}

Twelve moorings instrumented with acoustic reference transmitters were deployed within the study area during April 2010. One array of six moorings was located in shallow water (100-112 m) west of Portland Island in northern Stephens Passage, while a second array was deployed in deep water (574-585 m) southwest of Point Retreat in southern Lynn Canal (Fig. $1)$. The moorings of both arrays were spaced $200 \mathrm{~m}$ apart and positioned to form a 2 mooring $x 3$ mooring grid to maximize the data collected during the tracking surveys. Acoustic transmitters (Model MA-TP16-33, Lotek Wireless, Newmarket, Ontario, Can.), rated to a depth of $700 \mathrm{~m}$, were attached to the mooring line to provide acoustic signals at known locations and depths. The transmitters $(6.2 \mathrm{~cm}$ in length, $1.6 \mathrm{~cm}$ in diameter, and weighing 27 g) emitted a $76.8 \mathrm{kHz}$, code division multiple access (CDMA) signal burst every $2 \mathrm{~s}$ with power output of $155 \mathrm{~dB}$ (referenced to $1 \mu \mathrm{Pa}$ at $1 \mathrm{~m}$ ).

The transmitters were also equipped with a temperature sensor accurate to $\pm 0.8^{\circ} \mathrm{C}$ and depth sensor rated to 700 $\mathrm{m}$ depths and accurate to $\pm 10.5 \mathrm{~m}$. Sensor data were transmitted as part of the signal burst, and alternated every 2 $\mathrm{s}$ between depth and temperature. The transmitters were randomly selected and attached to the mooring at approximate depths of 20 and $100 \mathrm{~m}$ at the Portland Island site, and 20, 100, 200, and $500 \mathrm{~m}$ at the Point Retreat site. Transmitters were oriented perpendicular to the line (i.e., horizontal, as they would be if implanted in fish) and attached with electrical tape. The battery end of the transmitter was used as the attachment point so that the transducer was unobstructed.

Sablefish, Anoplopoma fimbria, and red king crab, Paralithodes camtschaticus, were captured and tagged with 


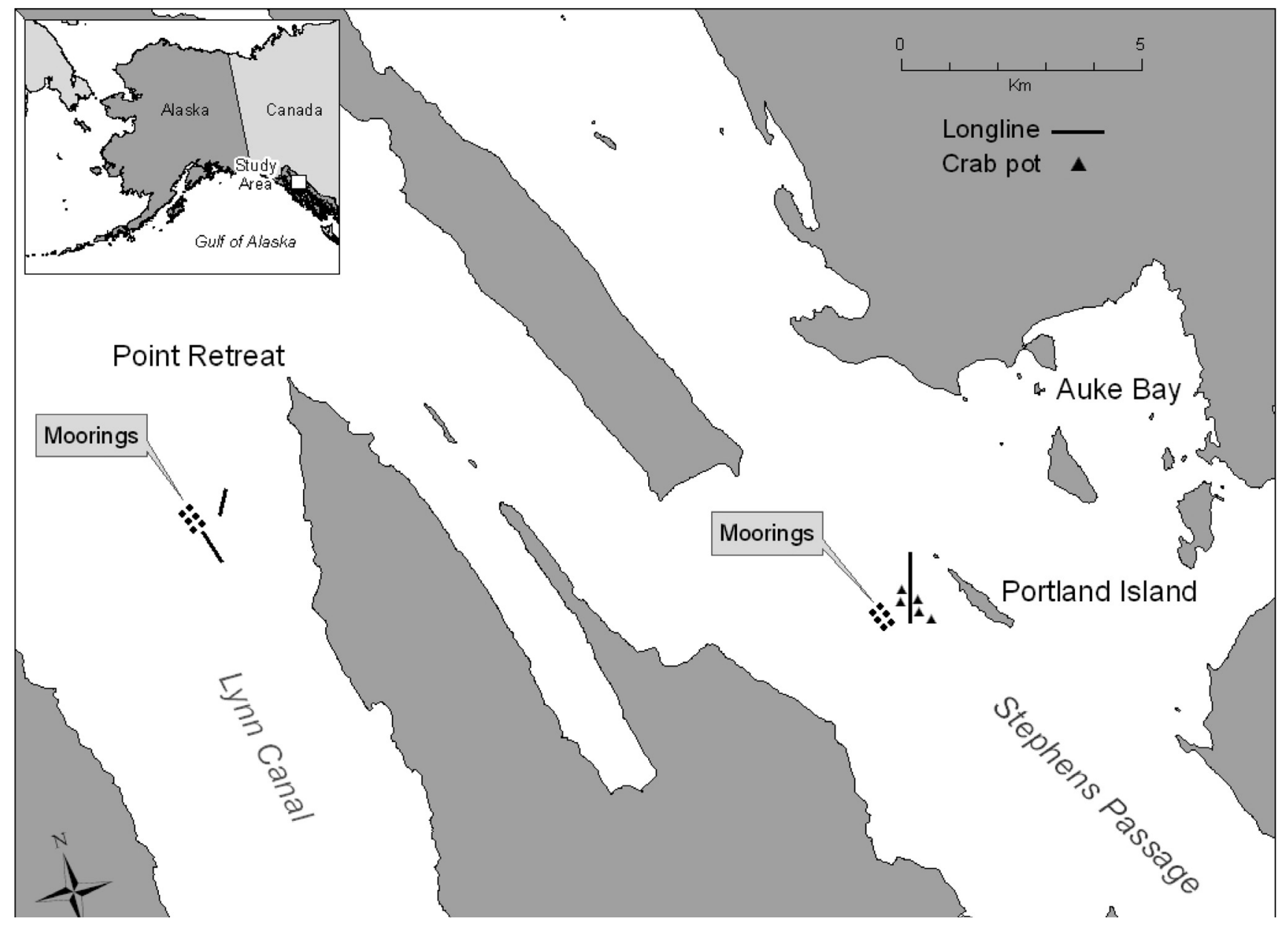

Figure 1.- The study area near Juneau, Alaska, showing the position of research moorings instrumented with acoustic transmitters. The location and type of fishing gear used to capture fish and crabs for tagging are also indicated. AUV and vessel-based tracking surveys were conducted in the vicinity of the moorings. Missions were also conducted in Auke Bay to calibrate equipment and refine tracking methods.

acoustic transmitters to supplement the reference transmitters and to provide acoustic targets with more realistic reception patterns. The crabs were captured with pyramidal crab pots (described by Browning, 1980) deployed and fished overnight near Portland Island at depths of 110-130 m (Fig. 1). Sablefish were captured with commercial longline gear (described by Skud and Hamley, 1978; Browning, 1980). The longline gear was retrieved $2-3 \mathrm{~h}$ after being deployed to minimize capture-related injuries and stress.

Selected individuals were tagged with acoustic transmitters (Model MM-M16-33, $6.4 \mathrm{~cm}$ x $1.6 \mathrm{~cm}, 29 \mathrm{~g}$
Lotek Wireless). These transmitters had the same signal characteristics as the reference transmitters, but were not equipped with temperature and depth sensors. Sablefish were tagged by surgically implanting transmitters in the abdominal cavity. ${ }^{2}$ Transmitters were attached externally to the dorsal carapace of the crabs using overlapping strips of Kevlar and fiberglass

${ }^{2}$ Eiler, J. H., T. M. Grothues, J. A. Dobarro, M. M. Masuda, D. W. Carlile, J. K. Nielsen, N. Hillgruber, and J. J. Vollenweider. 2011. Use of an autonomous underwater vehicle (AUV) for tracking acoustically-tagged fish in complex marine environments in coastal Alaska. NPRB Proj. 928 Final Rep. N. Pac. Res. Board, Anchorage, Alaska, $90 \mathrm{p}$. tape, saturated with quick-drying epoxy (Adtech EA-604 resin and hardener, Cass Polymers, Madison Heights, Mich.). Tagged crabs were held and observed for 1-2 $\mathrm{h}$ before release.

\section{Survey Operations}

Survey missions employed a REMUS 100 AUV (Hydroid, Inc., Pocasset, Maine, a subsidiary of Kongsberg Maritime, Kongsberg, Norway). This torpedo-shaped vehicle $(160 \mathrm{~cm}$ in length, $19 \mathrm{~cm}$ in diameter, $31 \mathrm{~kg}$ ) had a maximum operating depth of 100 $\mathrm{m}$ (although typically limited to $80-$ $85 \mathrm{~m}$ as a safeguard), cruising speed over ground of 0.25 to $2.57 \mathrm{~m} / \mathrm{s}$, and 
functional temperature range of $0^{\circ}$ to $38^{\circ} \mathrm{C}$ (Hydroid, 2007; Fig. 2). Operational parameters and mission instructions were programmed, simulated, and uploaded to the AUV prior to launch.

AUV navigation applied dead reckoning using data from the internal compass, yaw-rate sensor, propeller revolution rate, and sea bed reflections (bottom track) of the downward looking $1200 \mathrm{kHz}$ Acoustic Doppler Current Profiler/Doppler Velocity Log (ADCP/DVL, Teledyne RD Instruments, Poway, Calif.) to provide an estimate of speed-over-ground velocity and heading when within $30 \mathrm{~m}$ of the seafloor (Hydroid, 2007).

Course corrections were made by periodically surfacing to obtain position fixes using the vehicle's global positioning system (GPS) receiver. The AUV was either programmed to surface at designated locations or placed in "navigate" mode, which used complex software logic to determine when additional GPS fixes were needed based on an interpretation of the sensor data. An acoustic modem provided intermittent communication with the support vessel. An acoustic transmitter (same specifications as the reference transmitters) was also attached to the dorsal side of the vehicle and monitored by the same acoustic tracking gear installed on the support vessel for tracking tagged fish (see below); this approach provided independent and more frequent data on AUV position and depth than the modem, albeit at a reduced range. A radio transmitter attached to the AUV and RF receiver and directional antennas installed on the vessel were used to determine when the AUV surfaced and to relocate the vehicle for recovery.

In addition to the operational sensors, the AUV was instrumented with a $600 \mathrm{kHz}$ side-scan sonar (Marine Sonic Technology, Ltd., White Marsh, Va.), and sensors for measuring environmental conditions, including water conductivity and temperature (YSI, Inc. Yellow Springs, Ohio), pressure for estimating depth (Honeywell, Columbus, Ohio), dissolved oxygen (Aandreaa Data Instruments, Inc., Ber-

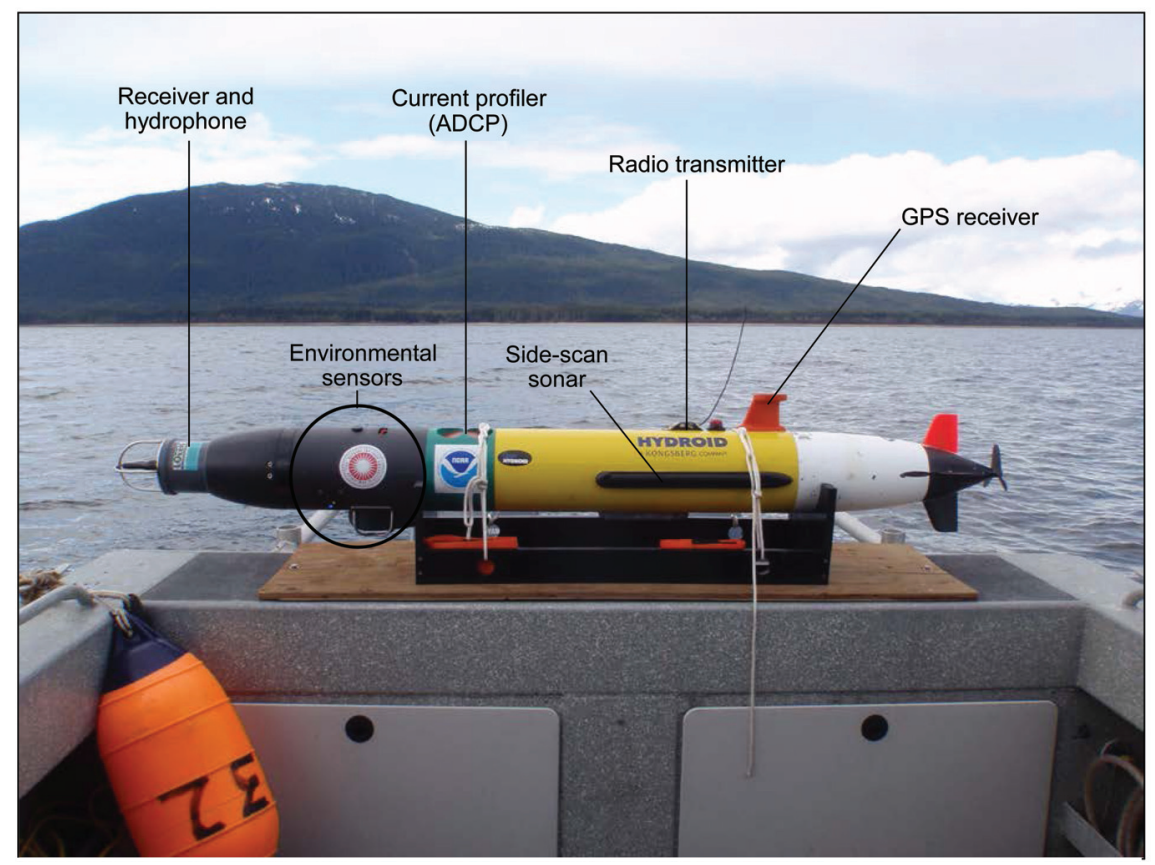

Figure 2.-REMUS 100 autonomous underwater vehicle (AUV) used to conduct tracking surveys in marine waters near Juneau, Alaska, during 2010. The AUV was equipped with a receiver and hydrophone for detecting and recording acoustic transmitters, environmental sensors, Acoustic Doppler Current Profiler/Doppler Velocity Log (ADCP/DVL), side-scan sonar, radio transmitter for locating the vehicle on the surface, and GPS receiver for collecting positioning data. The AUV was either launched from shore or transported to survey sites on a support vessel (shown above).

gen, Norway), and two triplet optical sensors (Wet Labs, Philomath, Oreg.). One optical sensor measured chlorophyll $a$, colored dissolved organic matter (CDOM), and backscatter at 880 $\mathrm{nm}$, while the second measured backscatter at $470 \mathrm{~nm}, 532 \mathrm{~nm}$, and 660 $\mathrm{nm}$. The vehicle was also equipped with an integrated acoustic receiver/ hydrophone (Model WHS 3050, Lotek Wireless) capable of detecting, identifying, and recording CDMA transmitter signals. The receiver was mounted to the forward bulkhead of the AUV with the hydrophone oriented horizontally (Fig. 2).

An $8 \mathrm{~m}$ aluminum boat was used to deploy and recover the AUV, and conduct vessel-based tracking surveys. The boat was instrumented with an acoustic receiver (Model MAP_600 RT, Lotek Wireless) and stereo hydrophones (Model LHP, Lotek Wireless) capable of detecting, identifying, and recording CDMA transmitter signals. The hydrophones were attached to vertical aluminum poles on the port and starboard (spaced $2 \mathrm{~m}$ apart) and submerged to $1 \mathrm{~m}$ depth. Tracking speed over ground ranged from 1.0 to 2.1 $\mathrm{m} / \mathrm{s}$ and was limited by oscillation of the poles at higher speeds. Position information for the boat was collected with a GPS receiver (Model GPSMap76CSX, Garmin, Olathe, Kan.).

Paired missions (i.e., tracking surveys with spatially and temporally similar routes for both the AUV and boat) were conducted in Stephens Passage near Portland Island and Lynn Canal near Point Retreat. Survey routes varied from zigzag to straight-line transects, with offsets (i.e., parallel distance) from the mooring grid ranging from 200 to $400 \mathrm{~m}$. During several missions the AUV was programmed to loiter (i.e., circle) at locations along the transect to enhance transmitter detec- 


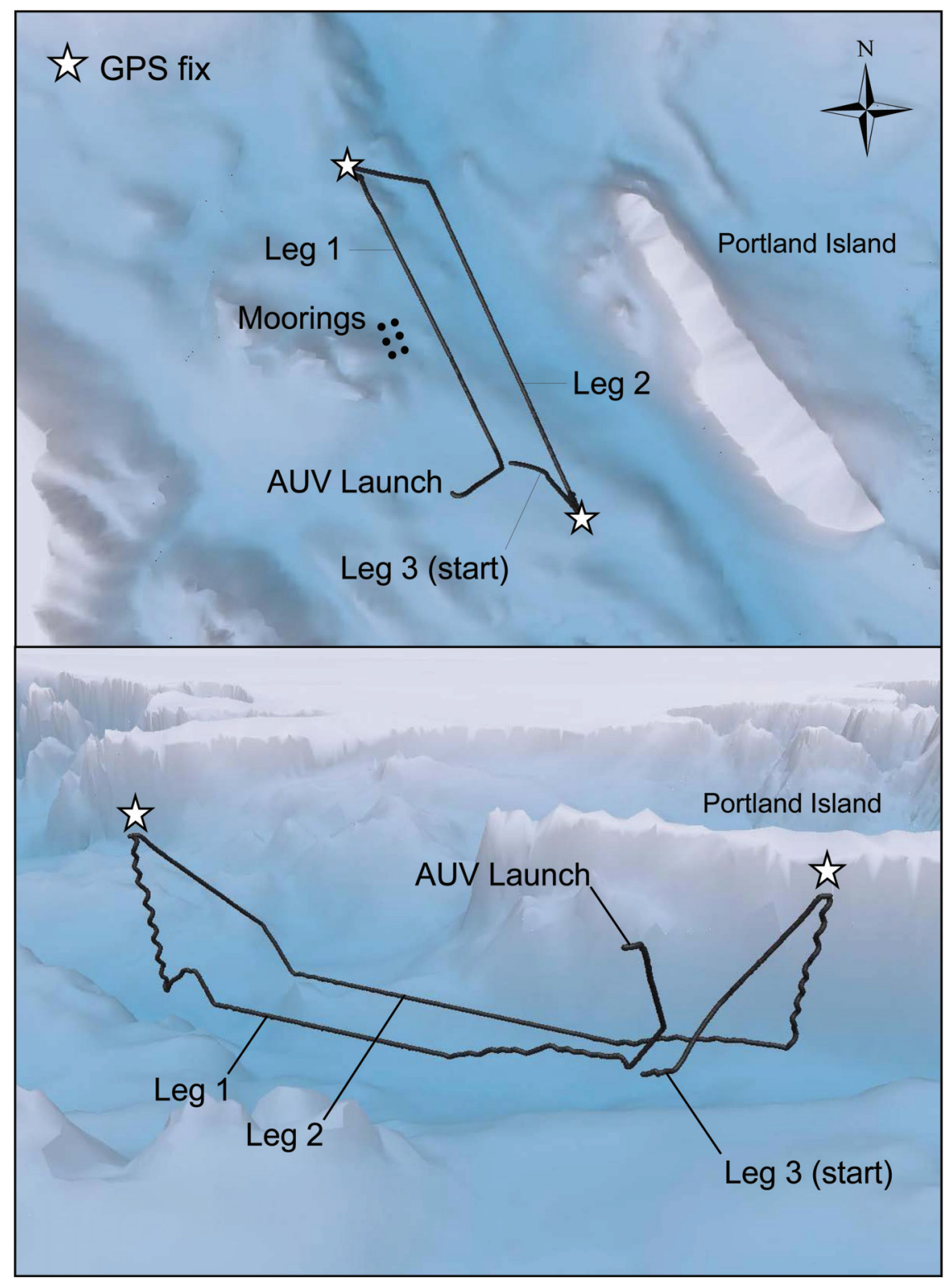

Figure 3.-AUV tracking mission conducted west of Portland Island near Juneau, Alaska (58.34 lat., $-134.78^{\circ}$ long.), during 2010 showing both the overhead (upper panel) and side (lower panel) view. The reference transmitter moorings, launch, recovery, and GPS fix locations are indicated. The AUV submerged to $80 \mathrm{~m}$ depth with programmed offset (parallel distance) from the mooring grid of $200 \mathrm{~m}$ (Leg 1) and $400 \mathrm{~m}$ (Leg 2), and surfaced at the end of each leg to obtain a GPS fix.

tions and position estimates. Transect length was approximately $2,700 \mathrm{~m}$, and both single and multiple-leg (i.e., sequential transects differentiated by a $180^{\circ}$ change in heading) missions were conducted (Fig. 3).

The AUV surveys were conducted between 30 and $80 \mathrm{~m}$ below the sur- acoustic modem and the acoustic telemetry gear (i.e., the boat's receiver and hydrophones, and the transmitter attached to the AUV) to actively monitor the position and depth of the submerged AUV. Telemetry data obtained during the AUV and boat surveys included time-stamped records identifying the reference transmitters and tagged animals detected, signal strength, environmental sensor data, and the corresponding position of the AUV and boat (latitude, longitude).

Both a fixed hydrophone (standard configuration used during the study with hydrophone at $1 \mathrm{~m}$ depth and oriented vertically) and towed hydrophone $(50 \mathrm{~m}$ cable attached to a support tether with an $18 \mathrm{~kg}$ weight, and hydrophone oriented horizontally) were used during a separate boat survey at Point Retreat to increase hydrophone depth and compare performance of these two vessel-based tracking methods. The hydrophones were connected to separate receivers and used concurrently to record reference transmitters within the area.

Depth varied for the towed hydrophone depending on the ambient currents and vessel speed over ground. Based on the angle of the tether, estimated depth averaged $3 \mathrm{~m}$ when traveling at speeds between 1.6 and $2.0 \mathrm{~m} / \mathrm{s}(3.2-4.0 \mathrm{kn})$ and $19 \mathrm{~m}$ for speeds between 1.0 and $1.3 \mathrm{~m} / \mathrm{s}$ $(2.0-2.5 \mathrm{kn})$, although fluctuations in depths were periodically observed due to interactions between vessel speed over ground, prevailing currents, and surface conditions. The orientation of the towed hydrophone, also indicated by the angle of the tether, ranged from nearly horizontal (3-8 $8^{\circ}$ at faster speeds to a depressed angle of $25-30^{\circ}$ at slower speeds. Ten consecutive, straight-line transects (five at the slower speed and five at the faster speed) were conducted, alternately running southeast and northwest with a $200 \mathrm{~m}$ offset from the transmitter moorings. Leg speed was randomly selected. Tracking success and the number of detections recorded were used to compare the two methods. 


\section{Data Analysis}

Tracking results for the paired missions were analyzed by mission leg. Legs where the AUV and boat remained parallel to the mooring grid (i.e., consistent offset distance) and where both tracks were spatially and temporally equivalent provided comparable data. AUV and boat tracks were evaluated using data visualization software (Eonfusion, Myriax, Inc., Hobart, Tasmania, Australia) to determine if these criteria (i.e., consistent offset distances from mooring, and spatially and temporally similar survey routes) were met. GPS readings recorded every 1-2 s provided an accurate track of the boat route. Since the AUV did not record GPS fixes while submerged, its route was recorded in an analogous $2 \mathrm{~s}$ interval from the dead reckoning computations. Position estimates were rectified in post processing. The error between the most recent calculated position at depth and the new GPS position acquired at surfacing was smeared across the submerged point estimates of that leg using the AUV host software's "RENAV" feature. Boat tracking data from the transmitter placed on the AUV (previously described) and comparisons of the expected (i.e., programmed) and actual start/end locations of the AUV were used to evaluate the veracity of the estimated route.

The tracking performance analysis was based primarily on telemetry data from the reference transmitters, which provided acoustic targets at known locations and depths. Observations of the mobile targets (i.e., tagged Sablefish and king crab) were used to supplement the reference transmitter data, since it was not possible to verify their actual positions. Tracking results were categorized in four ways: tracking success, detection rate, reception range, and transmitter signal strength (also referred to as signal power).

\section{Tracking Success}

Tracking success was defined as the proportion of reference transmit- ters deployed at each depth and study site that were detected at least once per mission leg. AUV and boat survey results were tested for differences in tracking success for transmitters deployed at shallow $(20 \mathrm{~m})$ and midwater $(100 \mathrm{~m})$ depths. Differences were apparent for transmitters at deeper depths (200 and $500 \mathrm{~m}$ ), and were not analyzed formally. Tracking success was modeled with a mixed-effects model (Pinheiro and Bates, 2002). Tracking method (AUV or boat) was treated as a fixed effect in the model. Missions and mission legs were treated as random effects, allowing the experimental units to be considered as being sampled from a larger population of units and for missions from the two study sites to reasonably be combined. Treating mission leg as a random effect rather than a replicate was also more realistic because sampling conditions could not be reasonably repeated during subsequent legs due to changes in tide stage, weather conditions, and other factors.

Analyses were performed separately for shallow $(20 \mathrm{~m})$ and mid-water (100 $\mathrm{m})$ depths. The sampling design was unbalanced as the numbers of legs were not equal among missions, and the tracking success proportions were arc-sine transformed prior to analysis to improve the homogeneity of variance (Neter and Wasserman, 1977). The models were fit using restricted maximum likelihood (REML) with the S-Plus statistical program (Version 7.0 for Windows TIBCO Spotfire Inc., Seattle, Wash.).

The normal mixed-effects model fit was defined as

$$
\begin{gathered}
y_{i j k}=\beta_{0}+\text { mission }_{i}+\operatorname{leg}_{j(i)}+ \\
\text { tracking }_{k}+\varepsilon_{i j k},
\end{gathered}
$$

where

$y_{i j k}=$ arc-sine transformed tracking success for the $j$-th leg of mission $i$ using the $k$-th tracking method;

$\beta_{0}=$ intercept;

mission $_{i}=i$-th mission effect;

$\operatorname{leg}_{j(i)}=j$-th leg effect of mission $i$; tracking $_{k}=$ mean for the $k$-th tracking method for the AUV or boat; mission $_{i} \sim N\left(0, \sigma_{a}^{2}\right)$;

$\operatorname{leg}_{j(i)} \sim N\left(0, \sigma_{b}^{2}\right)$;

$\varepsilon_{i j k} \sim N\left(0, \sigma_{e}^{2}\right) ;$ and

$i=1,2,3,4 ; j=1,2, \ldots, 7 ; 1,2$, $\ldots, 5$; or $1,2, \ldots, 8$; and $k=1,2$.

Errors were assumed mutually independent. The hypothesis test for the main fixed effect (tracking method) was $\mathrm{H}_{0}$ : tracking $_{1}=$ tracking $_{2}$. Diagnostic plots of standardized residuals (Pinheiro and Bates, 2002) from the fitted models were examined to assess the assumptions of constant variance and normality.

\section{Detection Rate}

Detection rate was defined as the number of reference transmitter detections recorded per minute during the mission leg. However, the time needed to complete a mission leg was not always the same for the AUV and boat due to differences in cruising speed over ground and ocean conditions. To make the tracking results comparable, the number of transmitter detections was standardized by the time the AUV and boat spent within reception range. Since the legs started before the transmitters were detected and ended as detections lessened, the time between the first and last record was used as a proxy for the time the AUV and boat spent within reception range.

Occasionally, sporadic detections occurred at extreme ends of a leg, which distorted the time estimates used in the analysis; therefore the first $2.5 \%$ and last $2.5 \%$ of the records were discarded for each leg and tracking method before calculating the time within reception range. No records were discarded if a tracking method at a particular depth recorded less than four detections. Only one case had less than four detections, and these were not at extreme ends of the track when compared with the other records. This procedure for standardizing the data was also used to compare reception range and power. 
The numbers of detections per minute were modeled the same as tracking success with a mixed-effects model (Equation 1). Specifically, $y_{i j k}$ was defined as the number of detections per minute for the $j$-th leg of mission $i$ using the $k$-th tracking method. The model was fit as described previously for tracking success.

\section{Reception Range}

Maximum range was defined as the greatest distance recorded from the transmitter to the vessel (AUV or boat), and was calculated as the hypotenuse of the horizontal distance from the vessel and the difference between the transmitter depth and vessel depth. Average maximum range was computed for each mission leg at each depth and study site. Maximum range for each leg was computed as the maximum ranges averaged over the detected transmitters. The three legs of Mission P8, which had no transmitters detected by the boat, were removed from the shallow-tag analysis since we were interested in the maximum range for detected transmitters.

Average maximum range was modeled the same as tracking success with a mixed-effects model (Equation 1). Specifically, $y_{i j k}$ was defined as the maximum range for the $j$-th leg of mission $i$ using the $k$-th tracking method averaged over detected tags. Since the modeled response of range was an average, variance weights in the model were defined as the numbers of observations used in computing the averages (Weisberg, 1985). Specifically, we assumed for Equation 1

$$
\varepsilon_{i j k} \sim N\left(0, \frac{\sigma_{e}^{2}}{n_{i j k}}\right)
$$

where

$$
\begin{aligned}
& n_{i j k}=\text { number of tags detected for } \\
& \text { the } j \text {-th leg of mission } i \text { using the } \\
& k \text {-th tracking method. }
\end{aligned}
$$

\section{Signal Strength (power)}

Average maximum power was computed for each mission leg at each depth and study site. Maximum power for each leg was computed the same as maximum range (i.e., the maximum power for detected transmitters was averaged over detected tags). Similar to range reception, the three legs of Mission P8 that had no transmitters detected by the boat were removed from the shallow-tag analysis since we were interested in the maximum power for detected transmitters. Average maximum power was modeled the same as tracking success with a mixed-effects model (Equation 1) and variance weights defined in Equation 2. Specifically, $y_{i j k}$ was defined as the maximum power for the $j$-th leg of mission $i$ using the $k$-th tracking method averaged over detected tags.

\section{Fixed vs. Towed Boat Hydrophones}

A normal mixed-effects model similar to Equation 1 was used to determine if hydrophone configuration (fixed vs. towed) and vessel speed were related to tracking success based on the auxiliary boat survey conducted at Point Retreat. Two of the variables defined previously were examined in this comparison: tracking success and detection rate. The number of reference transmitters (6) deployed at four depths $(20,100,200$, and $500 \mathrm{~m})$ was the same as in the AUV vs. boat surveys. However, since only one mission of this type was performed and only six transmitters were present at each depth, tracking success (proportion of reference transmitters detected at least once per leg) was computed by pooling over all depths.

The hydrophone configuration (fixed or towed) was treated in the model as a fixed effect and vessel speed as a continuous variable. As in Equation 1, the survey legs were treated as a random effect. The model fit to the tracking success data is as follows:

$$
\begin{gathered}
y_{i j}=\beta_{0}+\text { hydrophone }_{i}+\text { leg }_{j}+ \\
\beta_{1} \text { speed }_{i j}+\varepsilon_{i j},
\end{gathered}
$$

where

$y_{i j}=$ arc-sine transformed tracking success for the $j$-th leg using the $i$-th configuration of the hydrophone;

$\beta_{0}=$ intercept; hydrophone $_{i}=i$-th configuration of the hydrophone (fixed or towed); $\operatorname{leg}_{j}=j$-th leg effect;

$\beta_{1}=$ regression coefficient for average vessel speed;

speed $_{i j}=$ average vessel speed for the $i$-th configuration of the hydrophone and the $j$-th leg;

$$
\begin{aligned}
& \operatorname{leg}_{j} \sim N\left(0, \sigma_{b}^{2}\right) ; \\
& \varepsilon_{i j} \sim N\left(0, \sigma_{e}^{2}\right) ; \text { and } \\
& i=1,2 \text { and } j=1,2, \ldots, 10 .
\end{aligned}
$$

Errors were assumed mutually independent. The hypothesis test for the main fixed effect, the hydrophone configuration, was $\mathrm{H}_{0}$ : hydrophone ${ }_{1}=$ hydrophone $_{2}$, and the hypohesis test for the effect of vessel speed was $\mathrm{H}_{0}: \beta_{1}$ $=0$. The model was fit and diagnostics performed as described previously.

The fixed and towed hydrophones were also tested for a difference in detection rate- the number of reference transmitter detections recorded per minute during the survey leg. The duration of the survey leg was computed as the difference in time between the first and last transmitter detections. The detection rate was modeled the same as tracking success with a normal mixed-effects model (Equation 3). Specifically, $y_{i j}$ was defined as the number of detections per minute for the $j$-th leg using the $i$-th hydrophone configuration. Similar to the analysis of the AUV versus boat data, models were fit separately for shallow $(20 \mathrm{~m})$ and mid-water $(100 \mathrm{~m})$ depths. Very few transmitters were detected at 200 $\mathrm{m}$ and therefore the data were not analyzed formally, and no transmitters at $500 \mathrm{~m}$ were detected by either fixed or towed hydrophone.

\section{Results}

\section{Seawater Properties}

Water temperatures during the Portland Island missions averaged $7.1^{\circ} \mathrm{C}$ near the surface $(0-20 \mathrm{~m})$ and $5.3^{\circ} \mathrm{C}$ at deeper depths $(>40 \mathrm{~m})$. Although surface waters were warmer during later surveys near Point Retreat (averaging $8.5^{\circ} \mathrm{C}$ ), temperatures at deeper depths 

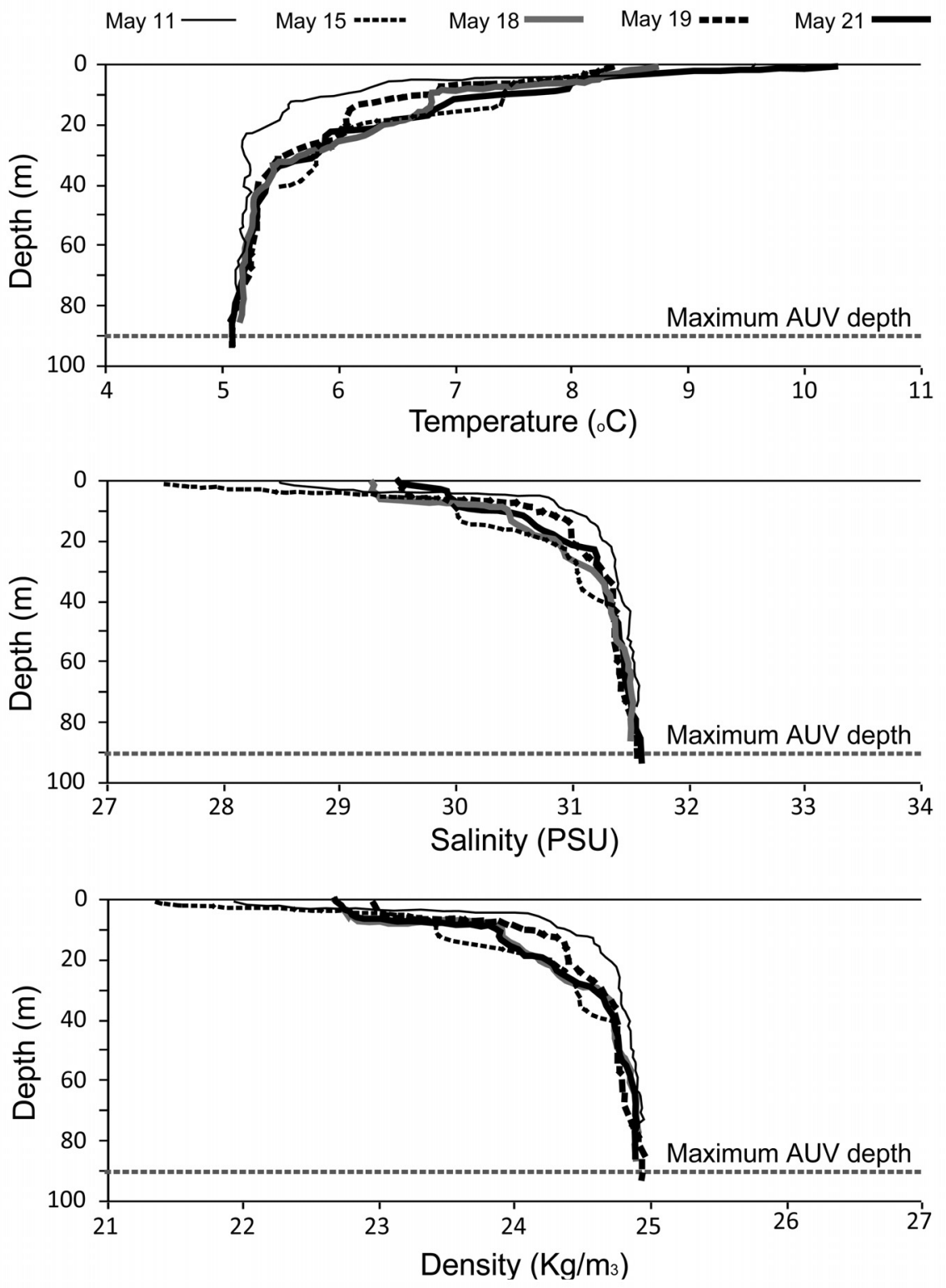

Figure 4.- Seawater properties determined from CTD (conductivity, temperature, and depth) data collected west of Portland Island near Juneau, Alaska, during May 2010. Water density is calculated using temperature and salinity data. Maximum operating depth for the AUV is indicated. Similar stratification patterns were observed at the Point Retreat site.

(average of $5.5^{\circ} \mathrm{C}$ ) were comparable to those observed near Portland Island. Sea surface salinity averaged 30.3 near Portland Island and 29.4 near Point Retreat, with averages of 31.4 and 33.3 at deeper depths. Water density averaged $23.7 \mathrm{~kg} \mathrm{~m}^{-3}$ and 22.8 $\mathrm{kg} \mathrm{m}^{-3}$ in surface waters, increasing to $24.8 \mathrm{~kg} \mathrm{~m}^{-3}$ and $26.2 \mathrm{~kg} \mathrm{~m}^{-3}$ at deeper depths. Surface waters were strongly stratified throughout the study, with a distinct thermocline, halocline, and pycnocline present in the upper $20 \mathrm{~m}$ (Fig. 4). The water column was more weakly stratified at deeper depths. For example, temperature differences near Portland Island and Point Retreat were greatest in the upper $20 \mathrm{~m},\left(2.9^{\circ} \mathrm{C}\right.$ and $\left.3.6^{\circ} \mathrm{C}\right)$ compared to $20-40 \mathrm{~m}\left(0.7^{\circ} \mathrm{C}\right.$ and $0.8^{\circ} \mathrm{C}$ ), and greater than $40 \mathrm{~m}$ depths $\left(0.2^{\circ} \mathrm{C}\right.$ and $\left.0.7^{\circ} \mathrm{C}\right)$. Similar trends were observed for salinity and density.

\section{AUV vs. Vessel-based Tracking Performance}

Four tracking missions, including two near Portland Island (P7 and P8) and two near Point Retreat (R2 and R3) were judged to have mission legs with comparable AUV and boat survey routes (spatially and temporally equivalent) that maintained a consistent offset from the transmitter moorings. The AUV submerged to a cruising depth of $80 \mathrm{~m}$ during missions P7, P8, and R3, and 50 $\mathrm{m}$ during Mission R2. Twenty-seven mission legs were used in the analysis, including 12 legs from Portland Island and 15 legs from Point Retreat.

\section{Tracking Success}

Tracking success (i.e., proportion of reference transmitters within the survey area detected during a leg) was significantly greater for the AUV than for the boat for transmitters deployed at both $20 \mathrm{~m}\left(F=105.8 \sim F_{1,26}, P<\right.$ $0.0001)$ and $100 \mathrm{~m}\left(F=10.5 \sim F_{1,26}, P\right.$ $=0.003)$. Diagnostic plots of standardized residuals from the model fits did not show strong evidence of non-constant variance or non-normality. The AUV was considerably more effective at detecting transmitters at deeper depth. Few transmitters were detected by the boat at $200 \mathrm{~m}$ depths, and only the AUV detected transmitters at 500 $\mathrm{m}$ depths (Fig. 5).

Confounding factors appeared to influence tracking success, especially during boat surveys. This was particularly evident during Mission P8 when no shallow $(20 \mathrm{~m})$ transmitters were detected by the boat during legs 2,4 , and 6 . The heading during these legs (southeast) was with the current, which presumably would have minimized turbulence around the boat's hydrophone and improved signal reception. The southeast legs during this mission were offset $400 \mathrm{~m}$ from the transmitter moorings versus a $200 \mathrm{~m}$ offset during the northwest legs (Fig. 


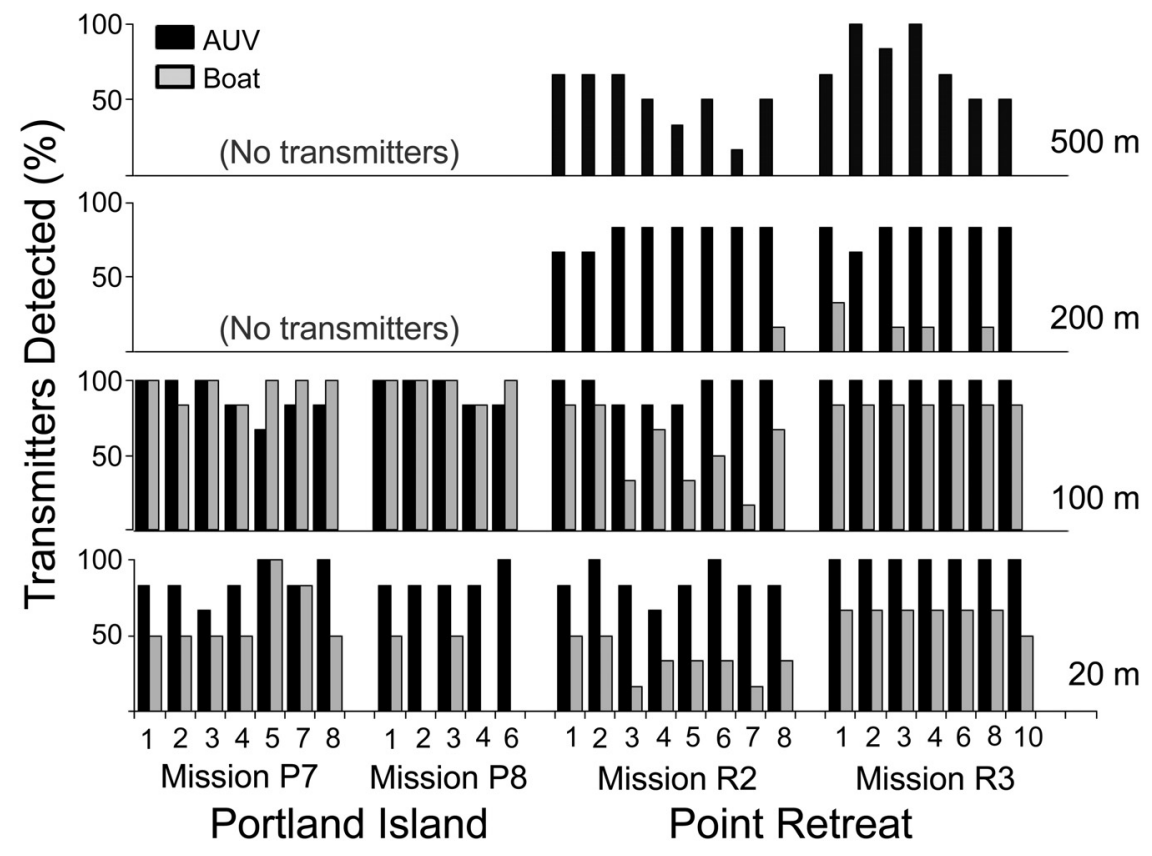

Figure 5.-Tracking success (percentage of the reference transmitters detected) by tracking method and mission leg for paired (AUV and boat) tracking missions in marine waters near Juneau, Alaska, during 2010. Transmitters were deployed at 20 and $100 \mathrm{~m}$ depths near Portland Island and from 20-500 m depths near Point Retreat. Transmitter depth is indicated in the right column legend. Mission legs excluded from the analysis are not shown.

3). However, transmitters at mid-water $(100 \mathrm{~m})$ depths were consistently recorded by the boat (Fig. 5) during both northwest and southeast legs, suggesting that other factors were involved.

Tracking success for the boat was consistently lower during Mission R2 than Mission R3. Similarly, the percentage of mid-water $(100 \mathrm{~m})$ transmitters recorded during southeast legs of Mission R2 was typically less than the northwest legs, again suggesting that local conditions influenced tracking results. Tracking success was remarkably similar for 20 and $100 \mathrm{~m}$ transmitters during Mission R3, particularly when compared with results from Mission R2. Differences in tracking success between and within AUV missions were minimal, especially for 20, 100, and $200 \mathrm{~m}$ transmitters (Fig. $5)$.

\section{Detection Rate}

The detection rate (i.e., the number of transmitter detections per minute mance is likely to be more reflective of differences associated with other factors.

\section{Reception Range}

Reception range (i.e., the maximum distance that the reference transmitters were recorded) for the AUV increased from 423 to $599 \mathrm{~m}$ for transmitters at 20 and $500 \mathrm{~m}$ depths, respectively (Fig. 7). During boat surveys, reception range averaged from $399 \mathrm{~m}$ for transmitters at shallow depths $(20 \mathrm{~m})$ to $626 \mathrm{~m}$ for transmitters at mid-water depths $(100 \mathrm{~m})$. The average maximum range was not significantly different between the AUV and boat for transmitters deployed at $20 \mathrm{~m}$ depths $(F=$ $1.8 \sim F_{1,23}, P=0.19$ ).

In contrast, average maximum range for transmitters at $100 \mathrm{~m}$ depths was significantly greater for the boat $(F$ $\left.=87.7 \sim F_{1,26}, P<0.0001\right)$. Diagnostic plots of standardized residuals from the model fits did not show strong evidence of non-constant variance or non-normality. The AUV and boat exhibited comparable reception range for transmitters deployed at 200 $\mathrm{m}$ depth, although this comparison should be viewed with caution since the boat estimate was based on only a small number of records. Only the AUV recorded transmitters at $500 \mathrm{~m}$ depth with an average reception range of $599 \mathrm{~m}$.

\section{Transmitter Signal Strength}

Maximum signal strength (power) showed a substantial decline with depth for transmitters recorded during the boat surveys. In contrast, power was relatively constant for transmitters recorded by the AUV at depths of 20, 100 , and $200 \mathrm{~m}$, and declined substantially for transmitters at $500 \mathrm{~m}$ depths (Fig. 7). Average maximum power was significantly greater for the AUV than for the boat for transmitters at $20 \mathrm{~m} \mathrm{(F}$ $\left.=12.2 \sim F_{1,23}, P=0.002\right)$ and $100 \mathrm{~m}$ $\left(F=213.7 \sim F_{1,26}, P<0.0001\right)$. Diagnostic plots of standardized residuals from the model did not show strong evidence of non-constant variance or non-normality. Power was substantially less for transmitters detected by 


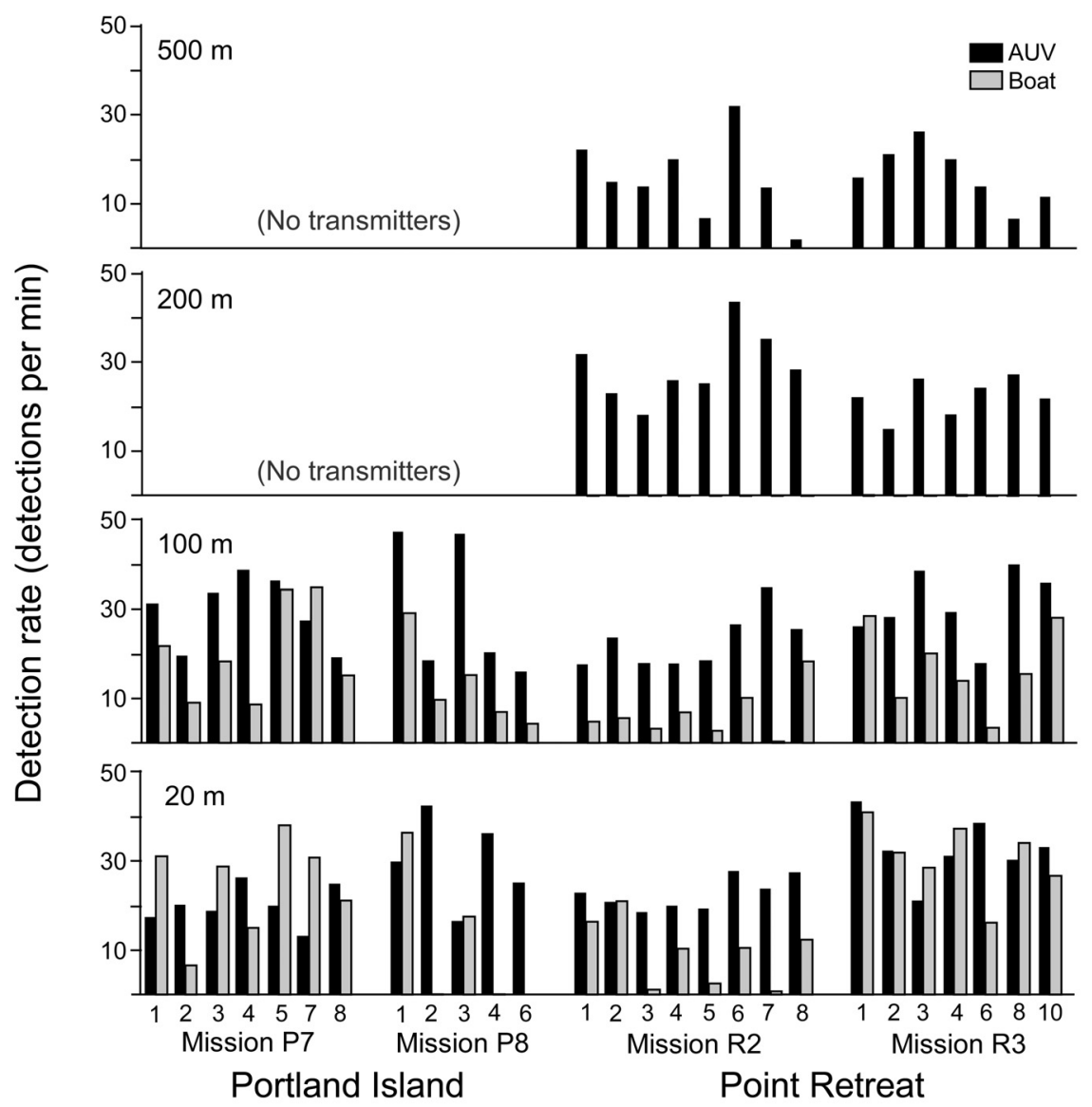

Figure 6.-Detection rate (number of reference transmitter detections recorded per min) by tracking method and mission leg for paired (AUV and boat) tracking missions in marine waters near Juneau, Alaska, during 2010. Transmitters were deployed at 20 and $100 \mathrm{~m}$ depths near Portland Island and from $20-500 \mathrm{~m}$ depths near Point Retreat. The boat detected too few transmitters at $200 \mathrm{~m}$ depths to be visible in this figure and no transmitters at $500 \mathrm{~m}$ depths. Mission legs excluded from the analysis are not shown.

the boat at $200 \mathrm{~m}$ depths, and only the AUV detected transmitters at $500 \mathrm{~m}$ depths.

\section{Reception Patterns}

Graphical displays of boat and AUV tracks showed different reception patterns. During boat surveys, transmitter detections were typically distributed widely along the transect route. In contrast, AUV detections were often truncated with relatively few transmitters detected on the periphery (Fig. 8). This pattern was not universal, suggesting that other factors were involved.

For example, AUV detections were more widely distributed during mis- end of the mission when the AUV had turned and was traveling to its recovery location.

\section{Mobile Targets}

Seven king crabs were tagged with acoustic transmitters and released in shallow water near Portland Island. The crabs, which had recently molted, averaged $197 \mathrm{~mm}$ in length, ranging from 185 to $210 \mathrm{~mm}$. A variety of fish were caught with longline gear, including 34 Sablefish. Ten Sablefish were tagged and released in deep water near Point Retreat. The fish averaged $683 \mathrm{~mm}$ in length, ranging from 640 to $775 \mathrm{~mm}$.

King crabs released near Portland Island were detected by both tracking methods. Three crabs were recorded during missions P7 and P8. One crab was recorded during every mission leg; the other two crabs were detected less frequently. The actual locations of the tagged individuals were not known, so the reception range was not determined. The AUV exhibited slightly better tracking success. Twenty-nine sightings (average $=2.1 \mathrm{crabs} / \mathrm{leg}$ ) were recorded by the AUV compared to 23 sightings (average $=1.6 \mathrm{crabs} / \mathrm{leg}$ ) for the boat. The number of detections recorded by the AUV during the paired missions was substantially greater, ranging from 4.3 to 5.8 times the number of detections observed during the boat surveys.

Tagged Sablefish released in deep water near Point Retreat were only detected by the AUV. Two tagged individuals were consistently recorded during the survey legs of Mission R2. A similar pattern was observed for legs 1-6 of Mission R3. No fish were detected during the last four legs of this survey, but these transects were conducted farther from the mooring grid and the fish may have been out of reception range.

\section{Tracking Performance using}

Fixed and Towed Boat Hydrophones parisons, may also have biased the reception range estimates. Incidental detections, at greater distances than those recorded during the mission legs, were occasionally made at the
Differences in vessel-based tracking performance were observed during the fixed and towed hydrophone comparison test conducted near Point Re- 

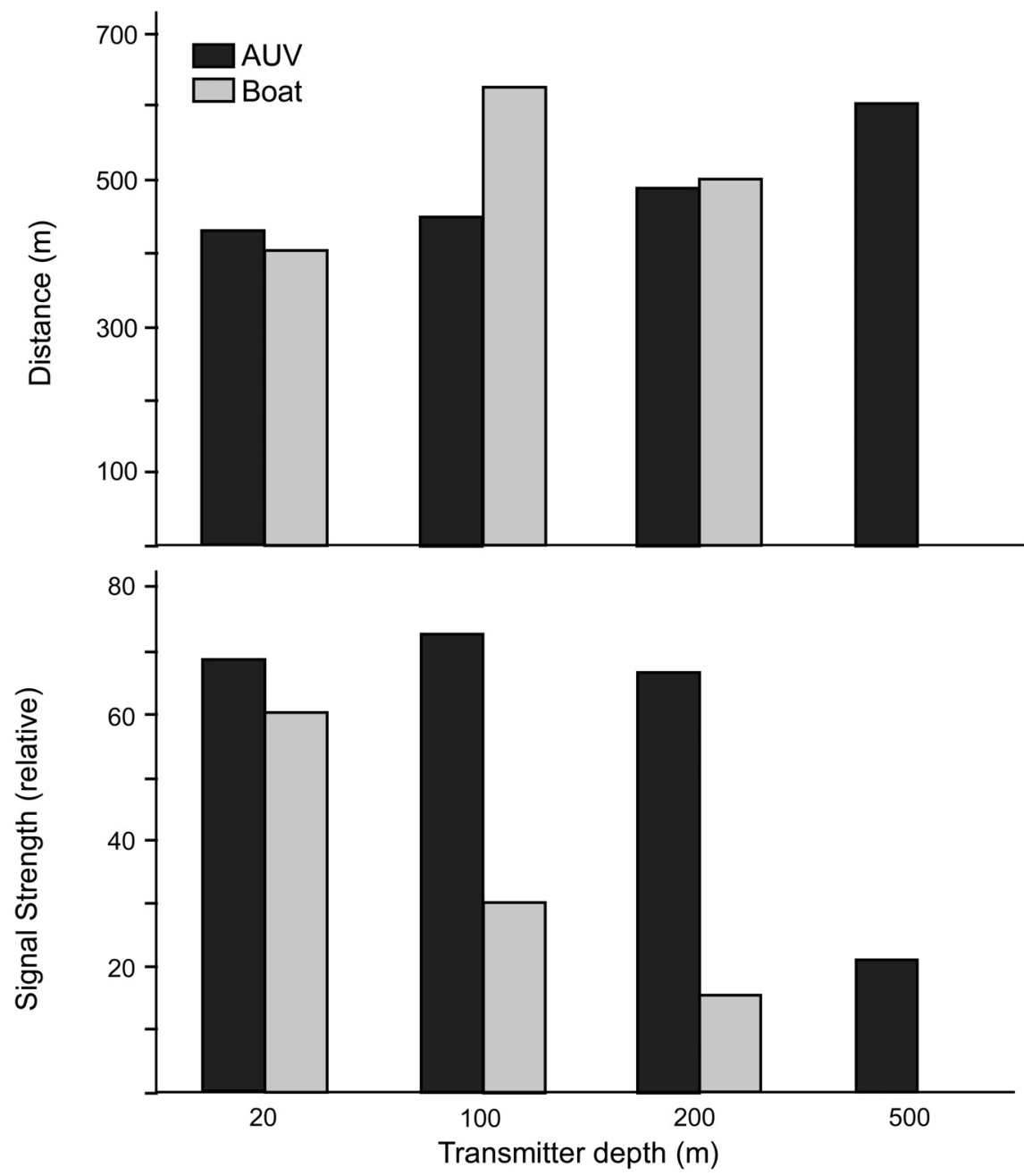

Figure 7.-Average maximum reception range (upper panel) and signal strength (lower panel) by tracking method and transmitter depth for reference transmitters detected during paired (AUV and boat) tracking missions in marine waters near Juneau, Alaska, during 2010.

treat. The fixed hydrophone exhibited significantly better tracking success $\left(F=13.4 \sim F_{1,9}, P=0.005\right)$, detecting an average of $45.1 \%$ of the reference transmitters present compared to $33.3 \%$ for the towed hydrophone (Table 1). Tracking success was not significantly related to vessel speed $\left(F=0.2 \sim F_{1,8}, P=0.66\right)$. Diagnostic plots of standardized residuals from the model fits did not show strong evidence of non-constant variance or non-normality.

With respect to detection rate, most $(85.6 \%)$ of the transmitters recorded during the survey were detected by the
Based on the normal mixed-effects model, the fixed hydrophone had significantly greater numbers of detections than the towed hydrophone at 20 m depth $\left(F=90.9 \sim F_{1,9}, P<0.001\right)$ and at $100 \mathrm{~m}$ depth $\left(F=68.3 \sim F_{1,9}\right.$, $P<0.001)$. Vessel speed was not a significant factor for both the $20 \mathrm{~m}$ transmitters $\left(F=1.2 \sim F_{1,8}, P=0.31\right)$ and $100 \mathrm{~m}$ transmitters $\left(F=3.6 \sim F_{1,8}, P=\right.$ 0.09 ). Diagnostic plots of standardized residuals from the model fits did not show strong evidence of non-constant variance or non-normality.

\section{Discussion}

Acoustic telemetry can provide detailed information on the distribution, movements, and habitat use of marine animals; however, tracking tagged individuals can be cumbersome and logistically challenging particularly in remote settings. The results of this study suggest that AUV's provide a viable alternative to conventional tracking methods. The four categories used to evaluate tracking performancetracking success, detection rate, reception range, and signal strengthprovided different insights into the capabilities of both vessel-based and AUV tracking methods.

\section{Performance Metrics}

Tracking success provided a direct measure of how effectively transmitters within the area were detected. Similarly, reception range provided functional information with direct application to field operations. Tracking success and range estimates are essential for designing and implementing effective tracking surveys, particularly in relation to the scope of the study and the time available for field operations (Grothues et al., 2005; Heupel et al., 2006; Simpfendorfer et al., 2008). The implications associated with detection rate (i.e., frequency that transmitters were detected) are more indirect, and are applicable when choosing the interval rate of the transmitter signal relative to the projected vehicle speed over ground and residence time within the signal radius during ensuing searches. 
More detections typically improve the accuracy of location estimates, assist in screening out erroneous data, and indicate potential tracking success under less favorable conditions (Hedger et al., 2008; Bergé et al., 2012; Nielsen et al., 2012). Signal strength, although limited in its application due to confounding factors (particularly environmental conditions), provides a relative measure of tracking success and reception range. Transmitters with greater signal strength are more likely to be detected and exhibit greater reception range under most conditions. Signal strength can also be used to judge relative proximity and thereby provide simple positioning solutions (Grothues et al., 2009), but the inherent limitations must be understood relative to other methods.

These metrics help shape the tactical design of mission features (speed over ground, depth, shape and radius of maneuvers for calculating position, and constrained optimization of path). They are also relevant to designing payload control algorithms, whereby an AUV executes maneuvers that interrupt the programmed mission based on the telemetry data collected.

Payload control stands to mitigate one of the major operational disadvantages of AUV's in comparison to vessel-based tracking: the inability to respond to the telemetry information collected in real time. This approach would be analogous to someone changing course after hearing a transmitter signal in order to obtain more detailed information, and has numerous applications. Payload control is capable of autonomously following a particular tagged animal in a simple estuarine system (Forney et al., 2012) and further algorithmic developments promise to yield additional improvement (Xydes et al., 2013).

\section{AUV-boat Comparison}

Overall tracking performance by the AUV was comparable or better than conventional vessel-based tracking. Tracking success and detection rate for the reference transmitters were significantly greater during the AUV surveys.

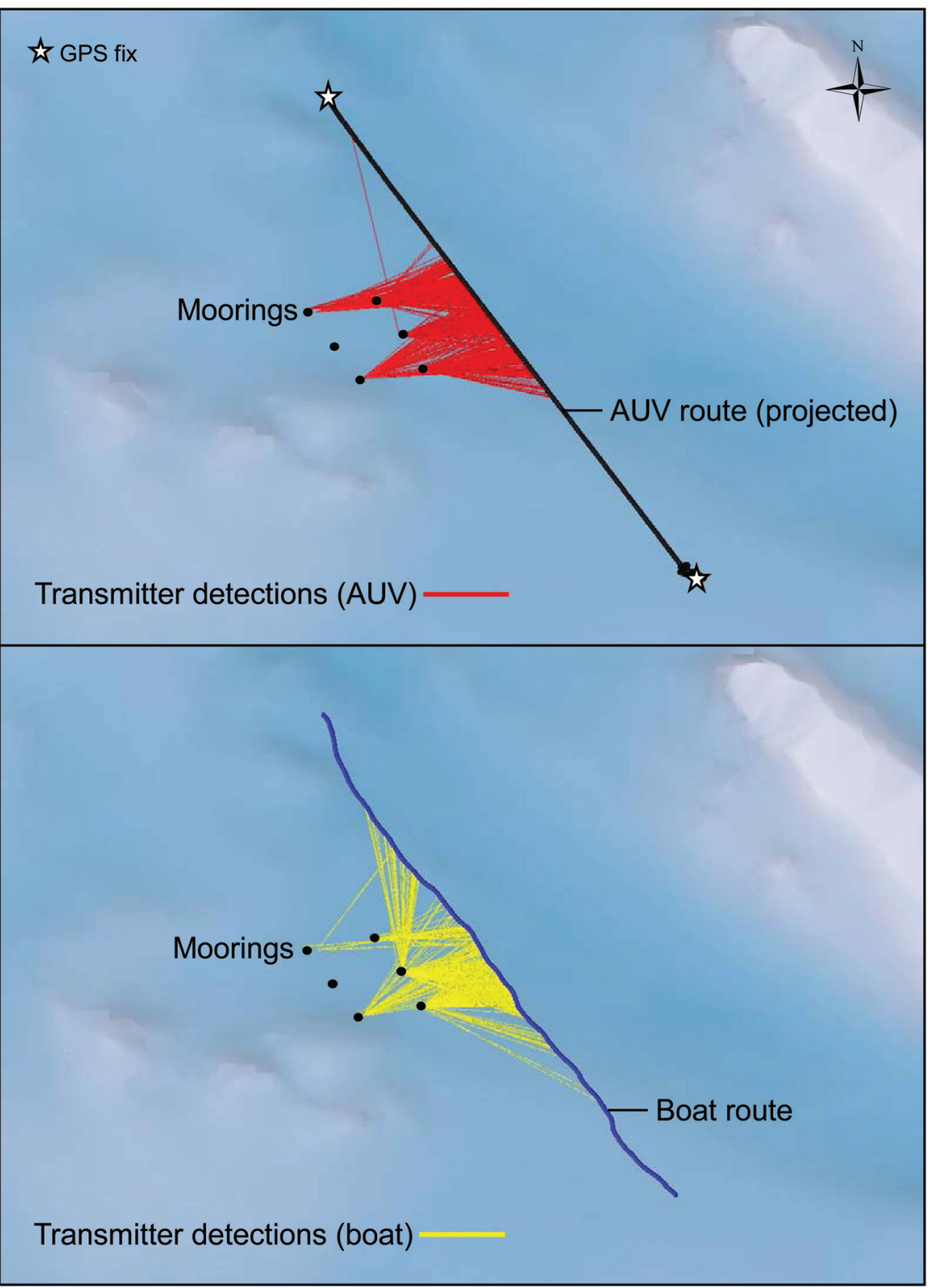

Figure 8.-Detection patterns (reference transmitters recorded along travel route) for the AUV (upper panel) and boat (lower panel) during a paired tracking mission conducted in marine waters west of Portland Island near Juneau, Alaska, during 2010. The reference transmitter moorings and GPS fixes for the AUV are indicated. The programmed offset (parallel distance) from the mooring grid for the AUV was $200 \mathrm{~m}$. The AUV route was projected based on GPS fixes at the beginning and end of the mission leg.

Although less definitive in shallow waters $(20 \mathrm{~m})$, better detection rates by the AUV were particularly notable for transmitters at mid-water $(100 \mathrm{~m})$ and deeper depths. Signal strength exhibited a similar pattern, with the AUV exhibiting comparable power levels for transmitters in shallow water, and substantially greater power levels at deeper depth. Similar patterns were also observed for the mobile targets (i.e., tagged king crab and Sablefish), although the tracking data were auxiliary due to the limited scope of the 
Table 1.-Tracking success (number and percentage of reference transmitters detected) for fixed and towed hydrophones during a vessel-based tracking survey in marine waters southwest of Point Retreat near Juneau, Alaska, during 2010. Twenty-four reference transmitters were present in the area. Mission leg and average vessel speed are indicated.

\begin{tabular}{lcrr}
\hline & & \multicolumn{2}{c}{ Number of transmitters detected $(\%)$} \\
\cline { 3 - 4 } Leg & Vessel speed $(\mathrm{m} / \mathrm{s})$ & Fixed hydrophone & Towed hydrophone \\
\hline L1 & 1.9 & $11(45.8)$ & $9(37.5)$ \\
L2 & 1.1 & $10(41.7)$ & $6(25.0)$ \\
L3 & 1.1 & $12(50.0)$ & $13(54.2)$ \\
L4 & 1.4 & $10(41.7)$ & $5(20.8)$ \\
L5 & 1.8 & $10(41.7)$ & $9(37.5)$ \\
L6 & 1.1 & $10(41.7)$ & $6(25.0)$ \\
L7 & 1.1 & $13(54.2)$ & $10(41.7)$ \\
L8 & 1.5 & $12(50.0)$ & $4(16.7)$ \\
L9 & 1.9 & $10(41.7)$ & $9(37.5)$ \\
L10 & 1.0 & $11(45.8)$ & $9(37.5)$ \\
& All speeds & $10.8(45.1)$ & $8.0(33.3)$ \\
\hline
\end{tabular}

surveys and restricted transect patterns used during the study. Additional investigation is needed to better assess tracking performance for free-ranging individuals.

The relationship between tracking method and reception range was less apparent. Reception range was comparable for both methods at shallower depths. However, boat surveys exhibited greater range for transmitters at greater depths, particularly those at $100 \mathrm{~m}$ (Fig. 7), even though the fixed hydrophones were positioned near the surface and presumably would have been better able to detect shallow (20 m) tags.

Although less pronounced, AUV reception range increased steadily with increasing transmitter depth. Acoustic signals can be attenuated by sea surface noise and deflected by stratification associated with water temperature, salinity, and density (Jensen et al., 1994; Berger et al., 2008). Ocean stratification was observed throughout the study, particularly in the upper $20 \mathrm{~m}$ (Fig. 4), and may have impacted signal transmission in this layer. This condition may explain the reduced reception range at shallower depths

The orientation of the hydrophone and straight-line survey pattern used during the study may also have been a factor. The boat hydrophones were mounted vertically on fixed struts, while the AUV hydrophone was oriented horizontally. The reception pattern of the hydrophone is essentially donut shaped, radiating out from the axis. When oriented horizontally, rein parentheses.

${ }^{1}$ Ranging $1.0-1.3 \mathrm{~m} / \mathrm{s}(2.0-2.5 \mathrm{kn})$.

${ }^{2}$ Ranging $1.6-2.0 \mathrm{~m} / \mathrm{s}(3.2-4.0 \mathrm{kn})$. by the boat at $200 \mathrm{~m}$ depths and the signals received were relatively weak. Only the AUV recorded reference transmitters at $500 \mathrm{~m}$ depths. Although these signals were also relatively weak, average reception range was actually greater than observed for transmitters at shallower depths, suggesting that other factors were involved; most likely the vehicle's reception pattern and the restricted survey routes used during the missions.

A similar pattern was observed for mobile transmitters in deeper water. Tagged Sablefish at depths in excess of $500 \mathrm{~m}$ were detected exclusively by the AUV. The ability of the AUV to distance itself from the ocean surface (and associated sea surface noise) and descend below stratified marine layers appears to be a major advantage. Mobile surveys conducted at deeper depths also reduce the distance between the tracking vehicle and the tagged fish, which can substantially enhance tracking performance particularly when studying demersal or deepwater pelagic species.

Although tracking performance is a critical consideration, the overall effectiveness of collecting telemetry data

Table 2.-Number of reference transmitter detections recorded by fixed and towed hydrophones during a vesselbased tracking survey in marine waters southwest of Point Retreat near Juneau, Alaska, during 2010. Mission leg, hydrophone type, and transmitter depth are indicated. Percentage by vessel speed and transmitter depth is

\begin{tabular}{|c|c|c|c|c|c|c|c|c|}
\hline \multirow[b]{3}{*}{ Leg } & \multicolumn{8}{|c|}{ Transmitter depth (m) } \\
\hline & \multicolumn{2}{|c|}{20} & \multicolumn{2}{|c|}{100} & \multicolumn{2}{|c|}{200} & \multicolumn{2}{|c|}{500} \\
\hline & Fixed & Towed & Fixed & Towed & Fixed & Towed & Fixed & Towed \\
\hline \multicolumn{9}{|c|}{ Slower vessel speeds ${ }^{1}$} \\
\hline L2 & 462 & 25 & 495 & 41 & 1 & 2 & 0 & 0 \\
\hline L3 & 528 & 213 & 642 & 189 & 9 & 37 & 0 & 0 \\
\hline L6 & 395 & 15 & 331 & 34 & 0 & 1 & 0 & 0 \\
\hline L7 & 476 & 123 & 647 & 119 & 13 & 0 & 0 & 0 \\
\hline L10 & 862 & 107 & 625 & 96 & 0 & 4 & 0 & 0 \\
\hline All legs & $\begin{array}{l}2723 \\
(84.9)\end{array}$ & $\begin{array}{c}483 \\
(15.1)\end{array}$ & $\begin{array}{l}2740 \\
(85.1)\end{array}$ & $\begin{array}{c}479 \\
(14.9)\end{array}$ & $\begin{array}{c}23 \\
(34.3)\end{array}$ & $\begin{array}{c}44 \\
(65.7)\end{array}$ & 0 & 0 \\
\hline \multicolumn{9}{|c|}{ Faster vessel speeds ${ }^{2}$} \\
\hline L1 & 355 & 9 & 341 & 41 & 2 & 0 & 0 & 0 \\
\hline L4 & 198 & 0 & 152 & 31 & 0 & 1 & 0 & 0 \\
\hline L5 & 117 & 3 & 135 & 33 & 0 & 1 & 0 & 0 \\
\hline L8 & 493 & 70 & 226 & 11 & 1 & 0 & 0 & 0 \\
\hline L9 & 208 & 81 & 106 & 24 & 0 & 1 & 0 & 0 \\
\hline All legs & $\begin{array}{l}1371 \\
(89.4)\end{array}$ & $\begin{array}{c}163 \\
(10.6)\end{array}$ & $\begin{array}{c}960 \\
(87.3)\end{array}$ & $\begin{array}{c}140 \\
(12.7)\end{array}$ & $\begin{array}{c}3 \\
(50.0)\end{array}$ & $\begin{array}{c}3 \\
(50.0)\end{array}$ & 0 & 0 \\
\hline \multicolumn{9}{|c|}{ All vessel speeds } \\
\hline Total & $\begin{array}{l}4094 \\
(86.4)\end{array}$ & $\begin{array}{l}646 \\
(13.6)\end{array}$ & $\begin{array}{l}3700 \\
(85.7)\end{array}$ & $\begin{array}{c}619 \\
(14.3)\end{array}$ & $\begin{array}{c}26 \\
(35.6)\end{array}$ & $\begin{array}{c}47 \\
(64.4)\end{array}$ & 0 & 0 \\
\hline
\end{tabular}


with AUV's is inextricably linked to its operational performance. Several problems were encountered during the study, ranging from functional limitations of the vehicle to mechanical and electrical issues. AUV performance was regularly impacted by local conditions. Travel route integrity was routinely compromised when traveling against strong currents, although the impact varied with the survey pattern. Maneuvers designed to provide good geometry for determining transmitter position were severely affected by cross currents and loiter loops typically exhibited downstream elongation or incomplete, offset loops downstream from the current. Navigation was frequently hampered by the lack of ADCP bottom lock for missions in water much deeper than the AUV's operational depth limit. A number of hardware and software-related issues were also encountered.

Mechanical problems also occur with boats, and many of the other issues encountered will undoubtedly be addressed as AUV manufacturing, use, and servicing become more routine. Furthermore, some problems experienced during the study, such as operations in deeper-than-specified waters and areas with adverse environmental conditions (e.g., prevailing currents in excess of $1 \mathrm{kn}$, changes in tide stage exceeding $4 \mathrm{~m}$ ), were knowingly self-imposed for the purpose of defining operational limits, and can be addressed by using AUV's with greater operating capabilities. Similar issues also apply to vessel-based operations in relation to vessel selection.

\section{Improving Boat Tracking}

Changes in equipment and tracking methods can circumvent some of the problems observed during this study with vessel-based tracking. Conventional boat tracking methods often utilize a move-stop-listen search pattern where the boat travels to a designated point and stops moving to reduce water turbulence around the hydrophone (to enhance signal reception) and collect telemetry data; the process is then repeated (e.g., $\mathrm{Ng}$ et al., 2007; Grothues et al., 2012).
While this approach can be effective, it is more time consuming compared to continuous surveys, particularly if the hydrophone is retracted from the water while in transit and must be redeployed. Tracking success is also dependent on the sampling interval and the reception range of the transmitters. Extended distances between sampling points can bias survey results, particularly when ambient conditions are less favorable and transmitter reception range is minimal or highly variable (Grothues et al., 2012).

However, sampling at shorter intervals is more time consuming, and can substantially reduce the area covered. Continuous but slower tracking speed would minimize this problem. However, unless tracking relatively sedentary species in localized areas, this approach has serious limitations; tracking mobile species over vast marine areas makes it necessary to cover extended distance in a reasonable period of time. Stronger structural supports to improve tracking speed when using fixed hydrophones and noise dampening techniques to lessen acoustic noise caused by water passing over the hydrophone (i.e., improving signal to noise ratio to increase transmitter reception) could substantially improve boat tracking success (Holland et al., 1985).

The comparison of vessel-based hydrophones (fixed vs. towed) during this study suggests that the fixed hydrophones provided better signal reception for transmitters at shallow and moderate depths (20 and $100 \mathrm{~m}$ ). Both methods exhibited either marginal performance or were ineffective for detecting transmitters at deeper depths (200 and $500 \mathrm{~m}$ ). Neither method was competitive with the AUV in terms of tracking success, overall reception range, signal strength, and tracking efficiency.

Fixed support structures provide precise information on the position, orientation, and depth of the hydrophone, substantially increasing the accuracy of the location estimates calculated for the transmitters. However, most fixed hydrophones are po- sitioned at relatively shallow depths, and are therefore more susceptible to increased signal attenuation and deflection due to turbulence, sea surface noise, and ocean stratification. Towed sensors have been used extensively to obtain information on ocean conditions, and an improved system for towing acoustic hydrophones at deeper depths could substantially enhance the detection of deepwater transmitters by reducing reception problems associated with proximity to the surface and stratification within the ocean strata (Jensen et al., 1994; Berger et al., 2008). Disadvantages with towed hydrophones compared to fixed hydrophones include the risk of becoming entangled, difficulties inherent in standardizing the relative position, orientation, and depth of the hydrophone, and increased signal loss with increasing hydrophone cable length. These factors can adversely impact the quality and interpretation of the data, and are exacerbated at greater depths.

\section{Future Research Needs}

Based on this study, merging AUV technology and acoustic telemetry presents a tremendous opportunity to expand research capabilities for monitoring marine populations, and provides a powerful tool for integrating distribution and movement data with habitat and environmental information. These results suggest that AUV's have a distinct advantage for studying demersal and deepwater pelagic species. AUV sensors also provide proximal information on surrounding conditions, making it possible to integrate fish telemetry data with geomorphic and environmental information. Advances in data visualization software show promise for integrating and displaying these complex and often unwieldy data.

Tracking fish with AUV's does present significant challenges, including increased reliance on vehicle performance and navigation systems, pre-mission programming (e.g., accurately specifying survey routes and objectives), and knowledge of the survey area. Operational problems with 
AUV's exist, but additional use, enhanced methods, and future advances will likely improve operational performance and assuage many of these limitations which are common to many AUV applications.

Additional work is also needed to further test the performance of telemetry systems for tracking fish. Specifically, more detailed information on system performance when the AUV is closer to the fish's depth and the ocean floor is needed, because there is potential for the change in angle between the tag's beam pattern (a directional sound pressure level bias: Grothues and Davis, 2013) to either increase or decrease positioning performance, or for bottom features to baffle transmission at the lower angle (Grothues et al., 2012).

Orientation of the hydrophone orthogonal to the AUV axis (presumably pointed at the seafloor) has never been compared and should be tested. This change could potentially resolve issues of baffling by the AUV's body and propeller, and also cause differences in the intercept geometries of the hydrophone's maximum sensitivity torus and the tag's beam pattern.

Payload control systems, by which data about ongoing tag detections is used to make navigation decisions, have been developed and tested for proof of concept (Forney et al., 2012), but only for following a single transmitter and never for the purpose of mapping multiple transmitters in a predefined search area. To the same end, search path geometries that maximize or find the best compromise between efficiency and the ability to accurately position a tag from synthetic aperture or sound pressure level methods (Nielsen et al., 2012; Grothues and Davis, 2013) should be modeled and then tested in situ on moving fish.

The use of a stereo hydrophone has likewise been tested for proof of concept on a small AUV, requiring an unwieldy boom system to separate the elements, but should be integrated in longer vehicles and tested against performance of single element systems in common environment trials to determine their value.

\section{Acknowledgments}

Partial funding for this study was provided by the North Pacific Research Board (Publication No. 456 for this article) and the NOAA Undersea Research Program at Rutgers University. In-kind support was provided by the NMFS Auke Bay Laboratories and Rutgers University's Institute of Marine and Coastal Sciences. We thank D. Carlile (Alaska Department of Fish and Game), J. Nielsen (University of Alaska, Fairbanks), M. DeLuca and J. Turnure (Rutgers University), and K. Cox, J. Maselko, J. Thedinga, and J. Vollenweider (NMFS) for assistance with fieldwork. N. Hillgruber (University of Alaska, Fairbanks) assisted with study planning. W. Metcalf provided valuable support designing, fabricating, and deploying the transmitter moorings and capturing fish for tagging. G. Garcia (NMFS) designed and fabricated equipment for the tracking surveys. L. Egan and P. O'Flaherty (Lotek Wireless) and L. Kuechle (Advanced Telemetry Systems) provided technical support for the telemetry portion of the project. L. Eisner assisted with processing and interpreting information on ocean conditions. The manuscript was critically reviewed by D. Carlile, E. Farley, and J. Thedinga. The findings and conclusions in the paper are those of the authors and do not necessarily represent the views of the NMFS.

\section{Literature Cited}

Arnold, G., and H. Dewar. 2001. Electronic tags in marine fisheries research: a 30-year perspective. In J. R. Sibert and J. L. Nielsen (Editors), Electronic tagging and tracking in marine fisheries, p. 7-64. Kluwer Acad. Publ., Dordrecht, The Netherlands.

Aschan M., M. Fossheim, M. Greenacre, and R. Primicerio. 2013. Change in fish community structure in the Barents Sea. PLoS ONE 8(4):e62748. [doi:10.1371/journal. pone.0062748].

Bergé, J., H. Capra, H. Pella, T. Steig, M. Ovidio, E. Bultel, and N. Lamouroux. 2012. Probability of detecting and positioning error of a hydro acoustic telemetry system in a fast-flowing river: intrinsic and environmental determinants. Fish. Res. 125-126:1-13.

Berger, C. R., S. Zhou, P. Willett, and L. Liu. 2008. Stratification effect compensation for improved underwater acoustic ranging. Inst. Electric. Electron. Eng. Trans. Signal Process. 56:3779-3783 [doi 10.1109/ TSP.2008.924801].

Bishop, M. A., B. F. Reynolds, and S. P. Powers. 2010. An in situ, individual-based approach to quantify connectivity of marine fish: ontogenetic movements and residency of lingcod. PLoS ONE 5(12):e14267. [doi:10.1371/journal.pone.0014267].

Brill, R., M. Lutcavage, G. Metzger, P. Bushnell, M. Arendt, J. Lucy, C. Watson, and D. Foley. 2002. Horizontal and vertical movements of juvenile bluefin tuna (Thunnus thynnus) in relation to oceanographic conditions of the western North Atlantic, determined with ultrasonic telemetry. Fish. Bull. 100(2):155-167.

Browning, R. J. 1980. Fisheries of the North Pacific: history, species, gear and processes. Alaska Northwest Publ. Co., Anchorage, 423 p.

Buckland, S. T. 1980. A modified analysis of the Jolly-Seber capture-recapture model. Biometrics 36:419-435.

Cadrin, S. X., and D. H. Secor. 2009. Accounting for spatial population structure in stock assessment: past, present, and future. In R. J. Beamish and B. J. Rothschild (Editors), The future of fisheries science in North America, p. 405-426. Fish Fish. Ser. 31, Springer, Heidelberg. [doi: 10.1007/978-1-4020-9210-7_22].

Clarke, M. E., C. Whitmire, E. Fruh, J. Anderson, J. Taylor, J. Rooney, S. Ferguson, and H. Singh. 2010. Developing the SeaBED AUV as a tool for conducting routine surveys of fish and their habitat in the Pacific. In Proceedings of 2010 IEEE/OES Autonomous Underwater Vehicles (AUV), Monterey, Calif., 5 p.

Doney, S. C., M. Ruckelshaus, J. E. Duffy, J. P. Barry, F. Chan, C. A. English, H. M. Galindo, J. M. Grebmeier, A. B. Hollowed, N. Knowlton, J. Polovina, N. N. Rabalais, W. J. Sydeman, and L. D. Talley. 2012. Climate change impacts on marine ecosystems. Annu. Rev. Mar. Sci. 4:11-37. [doi: 10.1146/ annurev-marine-041911-111611].

Forney, C. E. Manii, M. Farris, M. A. Moline, C. G. Lowe, and C. M. Clark. 2012. Tracking of a leopard shark with an AUV: sensor calibration and state estimation. In 2012 International Conference on Robotics and Automation, p. 5,315-5,321, Inst. Electric. Electron. Eng., St. Paul, Minn. [doi: 10.1109/ ICRA.2012.6224991]

Goethel, D. R., T. J. Quinn II, and S. X. Cadrin. 2011. Incorporating spatial structure in stock assessment: movement modeling in marine fish population dynamics. Rev. Fish. Sci. 19:119-136. [doi: 10.1080/10641262.2011.557451].

Goodman, L. 1990. Acoustic scattering from ocean microstructure. J. Geophys. Res. 95:11,573-11,573.

Grotheus, T. M., and K. W. Able. 2007. Scaling acoustic telemetry of bluefish in an estuarine observatory: detection and habitat use patterns. Trans. Am. Fish. Soc. 136:1,511-1,519. [doi: 10.1577/T06-155.1]

J. McDonnell, and M. Sisak. 2005. An estuarine observatory for real-time telemetry of migrant macrofauna: design, performance, and constraints. Limnol. Oceanogr. Meth. 3:275-289. 
and J. H. Pravatiner. 2012. Winter flounder (Pseudopleuronectes americanus Walbaum) burial in estuaries: acoustic telemetry triumph and tribulation. J. Exp. Mar. Biol. Ecol. 438:125-136. [doi:10.1016/j.jembe.2012.09.006] and W. C. Davis. 2013. Sound pressure level weighting of the center of activity method to approximate sequential fish positions from acoustic telemetry. Can. J. Fish. Aquat. Sci. 70(9):1,359-1,371.

J. Dobarro, A. Higgs, J. Ladd, G. Niezgoda, and D. Miller. 2009. Use of a multi-sensored AUV to telemeter tagged Atlantic sturgeon and map their spawning habitat in the Hudson River, USA. In Proc. 2008 Autonomous Underwater Vehicle (AUV) Workshop. Woods Hole Oceanogr. Inst., Woods Hole, Mass., 7 p. [doi: 10:1109/ AUV.2008.5347597]

J. H. Eiler, and J. Dobarro. 2010. Collecting, interpreting, and merging fish telemetry data from an AUV: remote sensing from an already remote platform. In Proc. Autonomous Underwater Vehicle 2010. Inst. Electrical Electronic Engr./Oceanic Engrg. Soc. Monterey, Calif., 9 p.

Hagen, P. E., N. Storkersen, K. Vestgard, and P. Kartvedt. 2003. The HUGIN 1000 autonomous underwater vehicle for military applications. In Proc. Oceans 2003, p. 1141-1145. Mar. Technol. Soc./Inst. Electrical Electronic Eng., San Diego, Calif.

Hedger, R. D., F. Martin, J. J. Dodson, D. Hatin, D., F. Caron and F. G. Whoriskey. 2008. The optimized interpolation of fish positions and speeds in an array of fixed acoustic receivers. ICES J. Mar. Sci. 65:1,248-1,259.

Heupel, M. R., J. M. Semmens, and A. J. Hobda. 2006. Automated acoustic tracking of aquatic animals: scales, design, and deployment of listening station arrays. Mar. Freshwater Res. 57:1-13.

Hibbert, L. 1997. Key to an ocean of information. Prof. Eng. 10:25-26.

Holland, K. N., R. W. Brill, J. S. Ferguson, R. K. Chang, R. Yost. 1985. A small vessel technique for tracking pelagic fish. Mar. Fish. Rev. 47(4):26-32.

Hydroid. 2007. REMUS 100 operations and maintenance manual, version 7.41a. Hydroid, Inc., Pocasset, Maine, 742 p.

Jensen, F. B., W. A. Kuperman, M. B. Porter, and $\mathrm{H}$ Schmidt. 1994. Computational ocean acoustics. AIP Press, N.Y., 612 p.

Jones, N. L., R. J. Lowe, G. Pawlak, D. A. Fong, and S. G. Monismith. 2008. Plume disper- sion on a fringing coral reef system. Limnol. Oceanogr. 53(5):2,273-2,286.

Marsac, F., and P. Cayre. 1998. Telemetry applied to behavior analysis of yellowfin tuna (Thunnus albacores, Bonnaterre, 1788) movements in a network of fish aggregating devices. Hydrobiologia 371/373:155-171.

Meyer, C. G., and K. N. Holland. 2005. Movement patterns, home range size and habitat utilization of the bluespine unicornfish, Naso unicornis (Acanthuridae) in a Hawaiian marine reserve. Environ. Biol. Fish. 73:201-210. [doi: 10.1007/s10641-005-0559-7].

Moline, M. A., S. M. Blackwell, C. von Alt, B. Allen, T. Austin, J. Case, N. Forrester, R. Goldsborough, M. Purcell, and R. Stokey. 2005. Remote environmental monitoring units: an autonomous vehicle for characterizing coastal environments. J. Atmos. Oceanic Technol. 22:1,797-1,808.

Neter, J., and W. Wasserman. 1977. Applied linear statistical models. Richard D. Irwin, Inc., Homewood, Ill., 842 p.

Ng, C. L., K. W. Able, and T. M. Grothues. 2007. Habitat use, site fidelity, and movement of adult striped bass in a southern New Jersey estuary based on mobile acoustic telemetry. Trans. Am. Fish. Soc. 136:1344-1355.

Nielsen, J. K., G. H. Niezgoda, S. J. Taggart, S J. Cooke, P. Anson, C. T. Hasler, and K. C. Hanson. 2012. Mobile positioning of tagged aquatic animals using acoustic telemetry with a synthetic hydrophone array (SYNAPS: Synthetic Aperture Positioning System). In J. McKenzie, B. Parsons, A. C. Seitz, R. K. Kopf, M. Mesa, and Q. Phelps (Editors), Advances in fish tagging and marking technology, p. 233-250. Am. Fish. Soc. Symp. 76, Besthesda, Md.

Pepperell, J. G., and T. L. O. Davis. 1999. Postrelease behavior of black marlin, Makaira indica, caught off the Great Barrier Reef with sportfishing gear. Mar. Biol. 135:369-380.

Perry, A. L., P. J. Low, J. R. Ellis, and J. D. Reynolds. 2005. Climate change and distribution shifts in marine fishes. Science 308:1,912-1,915.

Pincock, D. G., and S. V. Johnston. 2012. Acoustic telemetry overview. In N. S. Adams, J. W. Beeman, and J. H. Eiler, (Editors), Telemetry techniques: a user guide for fisheries research, p. 305-337. Am. Fish. Soc., Bethesda, Md

Pinheiro, J. C., and D. M. Bates. 2002. Mixedeffects models in $\mathrm{S}$ and S-Plus. Springer, N.Y., 528 p.
Rose, G. A. 2005. On distributional responses of North Atlantic fish to climate change. ICES J. Mar. Sci. 62:1,360-1,374. [doi: 10.1016/j. icesjms.2005.05.007].

Ross, T., and R. Lueck. 2003. Sound scattering from ocean turbulence. Geophys. Res. Letters 30(6):1,344-1,347. [doi:10.1029/2002GL016733].

Seber, G.A.F. 1982. The estimation of animal abundance and related parameters, 2nd ed. Griffin Publ., London, 654 p.

Simpfendorfer, C. A., M. R. Heupel, and R. E. Heuter. 2002. Estimation of short-term centers of activity from an array of omnidirectional hydrophones and its use in studying animal movements. Can. J. Fish. Aquat. Sci. 59:23-32

A. B. Collins. 2008. Variation formance of acoustic receivers and its implication for positioning algorithms in a riverine setting. Can. J. Fish. Aquat. Sci. 65:482-492.

Skud, B. E., and J. M. Hamley. 1978. Factors affecting longline catch and effort. Int. Pac. Halibut Comm. Sci. Rep. 64, 66 p.

Taggart, J. E., J. Mondragon, A. G. Andrews, and J. K. Nielsen. 2008. Spatial patterns and movements of red king and Tanner crabs: implications for the design of marine protected areas. Mar. Ecol. Prog. Ser. 365:151-163.

Voegeli, F. A., M. J. Smale, D. M. Webber, Y. Andrade, and R. K. O’Dor. 2001. Ultrasonic telemetry, tracking and automated monitoring technology for sharks. Environ. Biol. Fish. 60:267-281

Weisberg, S. 1985. Applied linear regression. John Wiley and Sons, N.Y., 324 p.

Welch, D. W., G. W. Boehlert, and B. R. Ward 2003. POST - the Pacific Ocean salmon tracking project. Oceanol. Acta 25:243-253.

Wernli, R. L. 2000. AUV commercializationwho's leading the pack? In Proc. Oceans 2000. Mar. Technol. Soc./IEEE, Providence, R.I., $5 \mathrm{p}$

Winter, J. D. 1996. Advances in underwater biotelemetry. In B. R. Murphy and D. W. Willis (Editors), Fisheries techniques, 2nd ed., p. 555-590. Am. Fish. Soc., Bethesda, Md.

Xydes, A., M. Moline, C. G. Lowe, T. J. Farrugia, and C. Clark. 2013. Behavioral characterization and particle filter localization to improve temporal resolution and accuracy while tracking acoustically tagged fishes. Ocean Eng. 61:1-11. [doi: 10.1016/j. oceaneng.2012.12.028] 